\title{
Office and ambulatory blood pressure control
} with a fixed-dose combination of candesartan and hydrochlorothiazide in previously uncontrolled hypertensive patients: results of CHILI CU Soon

\author{
This article was published in the following Dove Press journal: \\ Vascular Health and Risk Management \\ 9 December $201 \mathrm{I}$ \\ Number of times this article has been viewed
}

\section{Thomas Mengden' \\ Reinhold Hübner ${ }^{2}$ \\ Peter Bramlage ${ }^{3}$}

'Kerckhoff-Klinik GmbH, Bad

Nauheim, ${ }^{2}$ Takeda Pharma GmbH, Aachen, ${ }^{3}$ Institut für Kardiovaskuläre Pharmakologie und Epidemiologie, Mahlow, Germany
Correpondence: Thomas Mengden Kerckhoff-Klinik GmbH, Benekestrasse 2-8, 6I23I Bad Nauheim, Germany Tel +49 60329995908

$\mathrm{Fax}+496032999550$ I

Email t.mengden@reha.kerkchoff-kliniken.de
Background: Fixed-dose combinations of candesartan $32 \mathrm{mg}$ and hydrochlorothiazide (HCTZ) have been shown to be effective in clinical trials. Upon market entry we conducted a noninterventional study to document the safety and effectiveness of this fixed-dose combination in an unselected population in primary care and to compare blood pressure (BP) values obtained during office measurement (OBPM) with ambulatory blood pressure measurement (ABPM).

Methods: CHILI CU Soon was a prospective, noninterventional, noncontrolled, open-label, multicenter study with a follow-up of at least 10 weeks. High-risk patients aged $\geq 18$ years with previously uncontrolled hypertension were started on candesartan $32 \mathrm{mg}$ in a fixed-dose combination with either $12.5 \mathrm{mg}$ or $25 \mathrm{mg}$ HCTZ. OBPM and ABPM reduction and adverse events were documented.

Results: A total of 4131 patients $(52.8 \%$ male $)$ with a mean age of $63.0 \pm 11.0$ years were included. BP was $162.1 \pm 14.8 / 94.7 \pm 9.2 \mathrm{mmHg}$ during office visits at baseline. After 10 weeks of candesartan $32 \mathrm{mg} / 12.5 \mathrm{mg}$ or $25 \mathrm{mg}$ HCTZ, mean BP had lowered to $131.7 \pm 10.5 / 80.0 \pm 6.6 \mathrm{mmHg}$ ( $P<0.0001$ for both comparisons). BP reduction was comparable irrespective of prior or concomitant medication. In patients for whom physicians regarded an ABPM to be necessary (because of suspected noncontrol over 24 hours), ABP at baseline was 158.2/93.7 mmHg during the day and $141.8 / 85.2 \mathrm{mmHg}$ during the night. At the last visit, BP had significantly reduced to $133.6 / 80.0 \mathrm{mmHg}$ and $121.0 / 72.3 \mathrm{mmHg}$, respectively, resulting in $20.8 \%$ being normotensive over 24 hours $(<130 / 80 \mathrm{mmHg})$. The correlation between OBPM and ABPM was good ( $r=0.589$ for systolic BP and $r=0.389$ for diastolic BP during the day). Of those who were normotensive upon OBPM, 35.1\% had high ABPM during the day, 49.3\% were nondippers, and $3.4 \%$ were inverted dippers. Forty-nine adverse events $(1.19 \%)$ were reported, of which seven $(0.17 \%)$ were regarded as serious.

Conclusion: Candesartan $32 \mathrm{mg}$ in a fixed-dose combination with either $12.5 \mathrm{mg}$ or $25 \mathrm{mg}$ HCTZ is safe and effective for further BP lowering irrespective of prior antihypertensive drug class not being able to control BP.

Keywords: ambulatory blood pressure, office blood pressure, normalization, response

\section{Background}

Fixed-dose combinations of candesartan $32 \mathrm{mg}$ and hydrochlorothiazide (HCTZ) have been shown to be effective in clinical trials. ${ }^{1,2}$ Mean reductions in systolic blood pressure (SBP) and diastolic blood pressure (DBP) were significantly greater with candesartan $32 \mathrm{mg} / \mathrm{HCTZ} 25 \mathrm{mg}(21 / 14 \mathrm{mmHg})$ than with candesartan $32 \mathrm{mg}(13 / 9 \mathrm{mmHg})$ or HCTZ $25 \mathrm{mg}$ alone $(12 / 8 \mathrm{mmHg}){ }^{2}$ The addition of $12.5 \mathrm{mg}$ HCTZ or $25 \mathrm{mg}$ HCTZ 
to $32 \mathrm{mg}$ candesartan resulted in a further $\mathrm{BP}$ reduction by $13.0 / 8.8 \mathrm{mmHg}$ in the HCTZ $12.5 \mathrm{mg}$ group and by $15.5 / 10.0 \mathrm{mmHg}$ in the HCTZ $25 \mathrm{mg}$ group in a study by Bönner. ${ }^{3}$ At the same time, adverse events (AEs) were scarce, with about $1 \%$ serious AEs when candesartan combination therapy including HCTZ was considered. ${ }^{2,3}$

Upon market entry we aimed to conduct a non interventional study to document the safety and effectiveness of this fixed-dose combination in an unselected population in primary care. These non interventional studies complement the findings of prior controlled trials including typical patient groups in clinical practice and reflecting current treatment approaches and include patients not enrolled into prior trials because of high age, substantial cardiovascular risks, or concomitant medication. ${ }^{4}$

Within this context we considered it to be of considerable interest to compare the results on the effectiveness of office blood pressure measurement (OBPM) with data obtained during ambulatory blood pressure measurement (ABPM). This is of relevance because several studies have demonstrated that $\mathrm{BP}$ reduction achieved in non interventional studies is higher than that observed in randomized clinical trials. Further, ABP is more closely related to cardiovascular morbidity and target organ damage and may therefore have a greater prognostic value. ${ }^{5,6}$ In patients with uncontrolled hypertension, Salles et $\mathrm{al}^{7}$ showed that OBPM had no prognostic value, whereas ABPM correlated to cardiovascular morbidity and mortality.

\section{Patients and methods}

CHILI CU Soon was a prospective, noninterventional, noncontrolled, open-label, multi center study with a follow-up of at least 10 weeks. It was conducted by 1111 primary care physicians, internists, cardiologists, or diabetologists throughout Germany. The study was registered at the Bundesinstitut für Arzneimittel und Medizinprodukte (BfArM) and the Kassenärztliche Bundesvereinigung (KBV) in accordance with section 67(6) of the medicinal law. Applicable data protection Acts were respected. Participating physicians received remuneration for the documentation of patients, which was in accordance with the Gebührenordnung für Ärzte (GOÄ). Ethical approval was obtained prior to commencement of the study by the Freiburg Ethics Commission International, Germany, on March 23, 2009. Written informed consent was obtained from all patients.

\section{Patients}

High-risk patients aged at least 18 years were eligible for inclusion when a treatment decision had been made to start candesartan $32 \mathrm{mg}$ plus HCTZ $12.5 \mathrm{mg}$ or candesartan $32 \mathrm{mg}$ plus HCTZ $25 \mathrm{mg}$ due to arterial hypertension. Further inclusion criteria were uncontrolled BP ( $\geq 140 / 90 \mathrm{mmHg}$ or $\geq 130 / 80 \mathrm{mmHg}$ in patients with metabolic syndrome or diabetes), on prior antihypertensive therapy for at least 8 weeks, the presence of additional cardiovascular risk factors (eg, diabetes, dyslipidemia), and compliance with the prescribing information of Blopress ${ }^{\circledR} 32 \mathrm{mg}$ PLUS $12.5 \mathrm{mg}$ or Blopress $32 \mathrm{mg}$ forte PLUS $25 \mathrm{mg}$ (Takeda Pharma GmbH, Aachen, Germany). In case of an insufficient BP control at the first follow-up visit (at least 6 weeks after inclusion), physicians were allowed to increase the dose of HCTZ to $25 \mathrm{mg}$ (Blopress $32 \mathrm{mg}$ forte PLUS $25 \mathrm{mg}$ ). Any concomitant medication was allowed as necessary.

\section{Objectives}

The primary objective was to document a change in BP with the introduction of candesartan cilexetil $32 \mathrm{mg}$ and HCTZ $12.5 / 25 \mathrm{mg}$. Secondary objectives were (1) to document the proportion of patients who reach the target BP or are responders (DBP $<90$ or reduction by $\geq 10 \mathrm{mmHg}$ ) using OBPM, (2) to determine the change in BP stratified according to prior/concomitant therapies, and (3) to collect data on tolerability and drug safety in routine clinical practice.

\section{Variables}

Three visits were scheduled throughout a 10-week follow-up. At the first visit (enrollment), patient data, medical history, BP values, laboratory values, and previous and concomitant pharmacotherapy were documented. At the first follow-up visit (after 5-8 weeks), BP, concomitant pharmacotherapy, safety, and tolerability were assessed. At the last visit $(>10$ weeks after inclusion and at least 4 weeks after the first interim visit), BP, weight, body mass index, waist circumference, laboratory tests, prior and concomitant pharmacotherapy, and safety/tolerability were documented.

\section{Definitions}

Normal OBP was $<140 / 90 \mathrm{mmHg}$ for nondiabetic patients and $<130 / 80 \mathrm{mmHg}$ for diabetic patients or those with metabolic syndrome. Diastolic responders were defined at a DBP $<90 \mathrm{mmHg}$ or a reduction of at least $10 \mathrm{mmHg}$ vs baseline. Systolic responders were defined at a SDP $<140 \mathrm{mmHg}$ or a reduction of at least $20 \mathrm{mmHg}$ vs baseline.

Normal ABP values during the day were $<135 / 85 \mathrm{mmHg}$ and $<120 / 70 \mathrm{mmHg}$ during the night. Normal ABP values over 24 hours were $<130 / 80 \mathrm{mmHg}$. Normal dippers were 
those with a reduction of $\geq 10 \%$ and $<20 \%$ of the daytime mean during the night. Nondippers were those with a reduction between $\geq 0 \%$ and $<10 \%$ of the daytime mean. Inverted dippers were those with a reduction of $<0 \%$ of the mean during daytime or an increase at night. Extreme dipping was defined as a reduction at night that exceeded $20 \%$ of the values during the day.

\section{Statistics}

The case report forms were collected by the clinical research organization Factum GmbH, Offenbach, Germany, entered into a validated application based on ColdFusion MX 6.1 (Adobe Systems Incorporated, Seattle, WA), and saved on an SQL Server 2003 (Microsoft, Redmond, WA). Case report forms were checked for consistency and a subset of the forms verified with the source data $(8 \%)$.

Regarding safety, the trial was adequately sized $(n=5000)$ in order to identify rare AEs, ie, those that may not have been detected in previous clinical studies (incidence 1:1000), with a probability of $>95 \%$.

The statistical analysis was performed descriptively and was interpreted in an explorative way. Comparisons were made for a number of variables and analyzed using descriptive statistics. Differences were calculated in patients with values at baseline and follow-up (per protocol), for both the OBPM group and the ABPM group. The last documented visit was regarded to be the follow-up value in case only the interim visit was documented. Data were analyzed using IBM $^{\circledR}$ SPSS $^{\circledR}$ Statistics 18 (IBM Corporation, Somer, NY).
The tests applied are indicated in the legends of the tables and figures.

\section{Results}

Between June 2009 and December 2009 a total of 4131 patients were included (safety population), of which 4130 were available for the analysis (efficacy population). The mean age of all patients was $63.0 \pm 11.0$ years and $52.8 \%$ were male (Table 1 ). Frequent comorbid disease conditions were diabetes $(51.3 \%)$, coronary artery disease $(43.5 \%)$, angina pectoris $(26.2 \%)$, heart failure $(25.1 \%)$, and prior stroke $(23.5 \%)$.

\section{Blood pressure reduction with OBPM}

$\mathrm{BP}$ at baseline was $162.1 \pm 14.8 / 94.7 \pm 9.2 \mathrm{mmHg}$ (Table 2), which meant that $31.3 \%$ had mild, $48.4 \%$ moderate, and $18.8 \%$ severe hypertension. After about 10 weeks of candesartan $32 \mathrm{mg} / 12.5 \mathrm{mg}$ or $25 \mathrm{mg}$ HCTZ treatment, mean BP had lowered to $131.7 \pm 10.5 / 80.0 \pm 6.6 \mathrm{mmHg}(P<0.0001$ for both comparisons). A total of $91.0 \%$ were diastolic and $77.2 \%$ systolic responders, resulting in $31.2 \%$ normalization of those without diabetes or metabolic syndrome $(<140 / 90 \mathrm{mmHg})$ and $8.6 \%$ for those with diabetes or metabolic syndrome $(<130 / 80 \mathrm{mmHg})$. BP reduction was as effective in the total as in subgroups of patients defined by prior or concomitant medication (Table 3 ).

\section{Comparison of OBPM and ABPM values}

Physicians regarded ABPM to be necessary in 351 patients (because of suspected noncontrol over 24 hours).

Table I Baseline characteristics of the study population

\begin{tabular}{|c|c|c|c|c|}
\hline \multirow[t]{2}{*}{ Variables } & \multicolumn{2}{|c|}{ Patients with OBPM } & \multicolumn{2}{|c|}{ ABPM and OBPM } \\
\hline & No. available & $\%$ & No. available & $\%$ \\
\hline Males (\%) & 4130 & 52.8 & 351 & 57.5 \\
\hline Age (years $\pm S D)$ & 4128 & $63.0 \pm 11.0$ & 351 & $62.1 \pm 10.0$ \\
\hline Body mass index $\left(\mathrm{kg} / \mathrm{m}^{2} \pm \mathrm{SD}\right)$ & 4098 & $29.6 \pm 5.3$ & 350 & $30.3 \pm 7.1$ \\
\hline Waist circumference $(\mathrm{cm} \pm \mathrm{SD})$ & 3253 & $103.6 \pm 14.2$ & 318 & $104.5 \pm 13.1$ \\
\hline Smokers (\%) & 4102 & 20.3 & 351 & 25.9 \\
\hline \multicolumn{5}{|l|}{ Comorbid disease conditions } \\
\hline Diabetes (\%) & 3601 & 51.3 & $24 I$ & 53.5 \\
\hline Coronary artery disease (\%) & 3669 & 48.9 & 248 & 60.9 \\
\hline Angina pectoris (\%) & 3418 & 26.2 & 239 & 40.2 \\
\hline Heart failure (\%) & 3443 & 25.1 & 244 & 34.8 \\
\hline Stroke/TIA (\%) & 3322 & 23.5 & 232 & 33.1 \\
\hline Myocardial infarction (\%) & 3462 & 22.5 & 236 & 27.5 \\
\hline Peripheral arterial disease (\%) & 3371 & 15.4 & 232 & 20.3 \\
\hline Renal insufficiency (\%) & 3348 & 13.1 & 231 & 19.0 \\
\hline Neuropathy (\%) & 3322 & 10.5 & 233 & 16.3 \\
\hline Retinopathy (\%) & 3324 & 9.8 & 231 & 19.9 \\
\hline Atrial fibrillation (\%) & 3352 & 9.8 & 233 & 16.7 \\
\hline
\end{tabular}

Abbreviations: ABPM, ambulatory blood pressure measurement; OBPM, office blood pressure measurement; SD, standard deviation; TIA, transient ischemic attack. 
Table 2 Blood pressure values at baseline and follow-up

\begin{tabular}{|c|c|c|c|}
\hline \multirow[t]{2}{*}{ Variables } & \multicolumn{3}{|c|}{ All patients with OBPM } \\
\hline & Baseline & $\begin{array}{l}\text { Last visit } \\
\text { (LOCF) }\end{array}$ & $P$-value \\
\hline \multicolumn{4}{|l|}{ OBPM } \\
\hline $\mathrm{SBP}(\mathrm{mmHg})$ & $162.1 \pm 14.8$ & $131.7 \pm 10.5$ & $<0.0001$ \\
\hline $\mathrm{DBP}(\mathrm{mmHg})$ & $94.7 \pm 9.2$ & $80.0 \pm 6.6$ & $<0.0001$ \\
\hline Severity of hypertension (\%) & & & $<0.0001$ \\
\hline$<140 \mathrm{mmHg}$ and & 1.5 & 74.0 & \\
\hline \multicolumn{4}{|l|}{$<90 \mathrm{mmHg}(\%)^{\mathrm{a}}$} \\
\hline $140-159 \mathrm{mmHg}$ or & 31.3 & 23.0 & \\
\hline \multicolumn{4}{|l|}{$90-99$ mmHg (\%) } \\
\hline $160-179 \mathrm{mmHg}$ or & 48.4 & 2.7 & \\
\hline \multicolumn{4}{|l|}{$100-109$ mmHg (\%) } \\
\hline$\geq 180 \mathrm{mmHg}$ or & 18.8 & 0.3 & \\
\hline \multicolumn{4}{|l|}{$\geq 110 \mathrm{mmHg}(\%)$} \\
\hline \multicolumn{4}{|l|}{ Normalization/response (\%) } \\
\hline$<130 \mathrm{mmHg}$ and & 0.2 & 27.0 & $<0.0001$ \\
\hline \multicolumn{4}{|l|}{$<80 \mathrm{mmHg}(\%)^{\mathrm{b}}$} \\
\hline$<140 \mathrm{mmHg}$ and & 2.5 & 37.0 & $<0.000$ I \\
\hline \multicolumn{4}{|l|}{$<90 \mathrm{mmHg}(\%)^{\mathrm{c}}$} \\
\hline $\mathrm{DBP}<90 \mathrm{mmHg}$ or & & 91.0 & \\
\hline \multicolumn{4}{|l|}{$\Delta \geq 10 \mathrm{mmHg}(\%)$} \\
\hline $\mathrm{SBP}<140 \mathrm{mmHg}$ or & & 77.2 & \\
\hline$\Delta \geq 20 \mathrm{mmHg}(\%)$ & & & \\
\hline
\end{tabular}

Notes: aFor all patients; bfor patients with diabetes or metabolic syndrome; ffor patients without diabetes or metabolic syndrome.

Abbreviations: DBP, diastolic blood pressure; LOCF, last observation carried forward; OBPM, office blood pressure measurement; SBP, systolic blood pressure.

These patients were more likely to be male (57.5\% vs $52.8 \%)$ and smokers (25.9\% vs 20.3\%) and had a considerably higher burden of comorbid disease conditions such as coronary artery disease $(60.9 \%$ vs $48.9 \%)$, angina pectoris $(40.2 \%$ vs $26.2 \%$ ), heart failure (34.8\% vs $25.1 \%)$, and retinopathy (16.7\% vs 9.8\%) (Table 1).
In these patients, BP at baseline was $158.2 \pm 14.4$ / $93.7 \pm 10.0 \mathrm{mmHg}$ during the day and 141.8 \pm 16.9/85.2 \pm $10.5 \mathrm{mmHg}$ during the night (Table 4). At the last visit, BP was significantly reduced to $133.6 \pm 10.0 / 80.0 \pm 6.6 \mathrm{mmHg}$ and $121.0 \pm 12.2 / 72.3 \pm 7.4 \mathrm{mmHg}$, respectively, resulting in $20.8 \%$ being normotensive over 24 hours $(<130 / 80 \mathrm{mmHg})$.

The correlation between OBPM and ABPM was good with $r=0.589$ for SBP (Figure 1) and $r=0.389$ for DBP during the day (Figure 2).

Of those who were normotensive upon OBPM $(<140 / 90 \mathrm{mmHg}), 35.1 \%$ had high ABPM during the day, $49.8 \%$ were nondippers, and $3.4 \%$ were inverted dippers (Table 5). Of those who were hypertensive during their office visit, $21.1 \%$ had a normal BP during ABPM at daytime and $7.1 \%$ at nighttime. Again, there was a larger subset whose BP pattern was compatible with a nondipping or inverted dipping pattern.

\section{Number of patients with (serious) adverse events}

The mean serum potassium value was $4.41 \pm 0.55$ at baseline and $4.36 \pm 0.63$ at follow-up. This was a statistically significant reduction of the mean serum potassium $(P=0.013)$. This was reflected in $10.6 \%$ with hyperkalemia at baseline and only $7.8 \%$ during follow-up. Reductions were also significant in the subgroup of patients with only candesartan as a renin-angiotensin system blocker but not in those receiving two different renin-angiotensin system blocking agents. A direct comparison, however, yielded no significant results $(P=0.476)$. During the course of the observation, 49 AEs were reported in patients receiving a fixed combination of

Table 3 Change in blood pressure (OBPM, $n=4130$ ) stratified according to prior visit/concomitant therapies

\begin{tabular}{|c|c|c|c|c|}
\hline & \multicolumn{2}{|l|}{ SBP } & \multicolumn{2}{|l|}{ DBP } \\
\hline & $\Delta \mathbf{S B P}$ & $P$-value vs baseline & $\triangle \mathrm{DBP}$ & $P$-value vs baseline \\
\hline \multicolumn{5}{|c|}{ Prior but discontinued therapies } \\
\hline ACE inhibitors & $-30.7 \pm 14.8$ & $<0.0001$ & $-15.4 \pm 9.6$ & $<0.0001$ \\
\hline Angiotensin receptor blockers & $-27.9 \pm 14.8$ & $<0.0001$ & $-13.2 \pm 9.7$ & $<0.000$ I \\
\hline Beta blockers & $-31.3 \pm 16.3$ & $<0.0001$ & $-15.5 \pm 10.3$ & $<0.0001$ \\
\hline $\mathrm{CCBs}$ & $-31.2 \pm 15.7$ & $<0.0001$ & $-15.1 \pm 10.5$ & $<0.000$ I \\
\hline Diuretics & $-30.6 \pm 16.1$ & $<0.0001$ & $-15.2 \pm 10.0$ & $<0.000$ I \\
\hline None & $-30.1 \pm 17.5$ & $<0.0001$ & $-16.3 \pm 11.8$ & $<0.000$ I \\
\hline \multicolumn{5}{|l|}{ Prior and continued therapies } \\
\hline ACE inhibitors & $-30.4 \pm 15.4$ & $<0.0001$ & $-14.3 \pm 8.9$ & $<0.0001$ \\
\hline Angiotensin receptor blockers & $-25.3 \pm 25.8$ & $<0.0001$ & $-9.0 \pm 14.8$ & $<0.000$ I \\
\hline Beta blockers & $-30.2 \pm 16.2$ & $<0.0001$ & $-14.3 \pm 10.6$ & $<0.000$ I \\
\hline $\mathrm{CCBs}$ & $-30.6 \pm 16.4$ & $<0.0001$ & $-14.2 \pm 10.6$ & $<0.000$ I \\
\hline Diuretics & $-29.9 \pm 16.9$ & $<0.0001$ & $-13.3 \pm 11.2$ & $<0.000$ I \\
\hline
\end{tabular}

Abbreviations: ACE, angiotensin-converting enzyme; CCB, calcium channel blocker; DBP, diastolic blood pressure; OBPM, office blood pressure measurement; SBP, systolic blood pressure. 
Table 4 Blood pressure values at baseline and follow-up

\begin{tabular}{|c|c|c|c|}
\hline \multirow[t]{2}{*}{ Variables } & \multicolumn{3}{|c|}{ Patients with ABPM } \\
\hline & Baseline & Last visit (LOCF) & $P$-value \\
\hline \multicolumn{4}{|l|}{ ABPM day } \\
\hline Systolic blood pressure $(\mathrm{mmHg})$ & $158.2 \pm 14.4$ & $133.6 \pm 10.6$ & $<0.000$ I \\
\hline Diastolic blood pressure $(\mathrm{mmHg})$ & $93.7 \pm 10.0$ & $80.0 \pm 6.6$ & $<0.000$ I \\
\hline \multicolumn{4}{|l|}{ ABPM night } \\
\hline Systolic blood pressure $(\mathrm{mmHg})$ & $141.8 \pm 16.9$ & $121.0 \pm 12.2$ & $<0.000$ I \\
\hline Diastolic blood pressure $(\mathrm{mmHg})$ & $85.2 \pm 10.5$ & $72.3 \pm 7.4$ & $<0.000$ I \\
\hline \multicolumn{4}{|l|}{ ABPM 24 hours mean } \\
\hline Systolic blood pressure $(\mathrm{mmHg})$ & $151.7 \pm 13.7$ & $128.9 \pm 10.2$ & $<0.000$ I \\
\hline Diastolic blood pressure $(\mathrm{mmHg})$ & $90.4 \pm 9.0$ & $77.5 \pm 6.4$ & $<0.000$ I \\
\hline Severity of hypertension & & & $<0.000$ I \\
\hline$<135 \mathrm{mmHg}$ and $<85 \mathrm{mmHg}(\%)$ & 0.9 & 53.0 & \\
\hline 135-146 mmHg or $85-89 \mathrm{mmHg}(\%)$ & 6.0 & 33.6 & \\
\hline $147-156 \mathrm{mmHg}$ or $90-95 \mathrm{mmHg}(\%)$ & 29.3 & 10.3 & \\
\hline$\geq 157 \mathrm{mmHg}$ or $\geq 96 \mathrm{mmHg}(\%)$ & 63.8 & 3.1 & \\
\hline
\end{tabular}

Abbreviations: ABPM, ambulatory blood pressure measurement; LOCF, last observation carried forward.

$32 \mathrm{mg}$ candesartan with either $12.5 \mathrm{mg} \mathrm{HCTZ}$ or $25 \mathrm{mg}$ HCTZ ( $n=49 / 4131 ; 1.19 \%)$. Of these, seven $(0.17 \%)$ were regarded as serious. Most AEs were related to the nervous system $(\mathrm{n}=13 ; 0.31 \%)$ or cardiac disorders $(\mathrm{n}=12$; $\mathrm{n}=0.29 \%)$. Details are displayed in Table 6 (MedDRA $^{\circledR}$ Primary System Organ Classes, Northrop Grummon Corporation, California, US).

\section{Discussion}

CHILI CU Soon demonstrated that $32 \mathrm{mg}$ candesartan in combination with $12.5 \mathrm{mg} \mathrm{HCTZ}$ or $25 \mathrm{mg} \mathrm{HCTZ}$ is safe and effective at lowering BP in patients who are uncontrolled on prior antihypertensive therapy. Patients were at high cardiovascular risk, as exemplified by the high prevalence of diabetes, angina pectoris/coronary artery disease, and

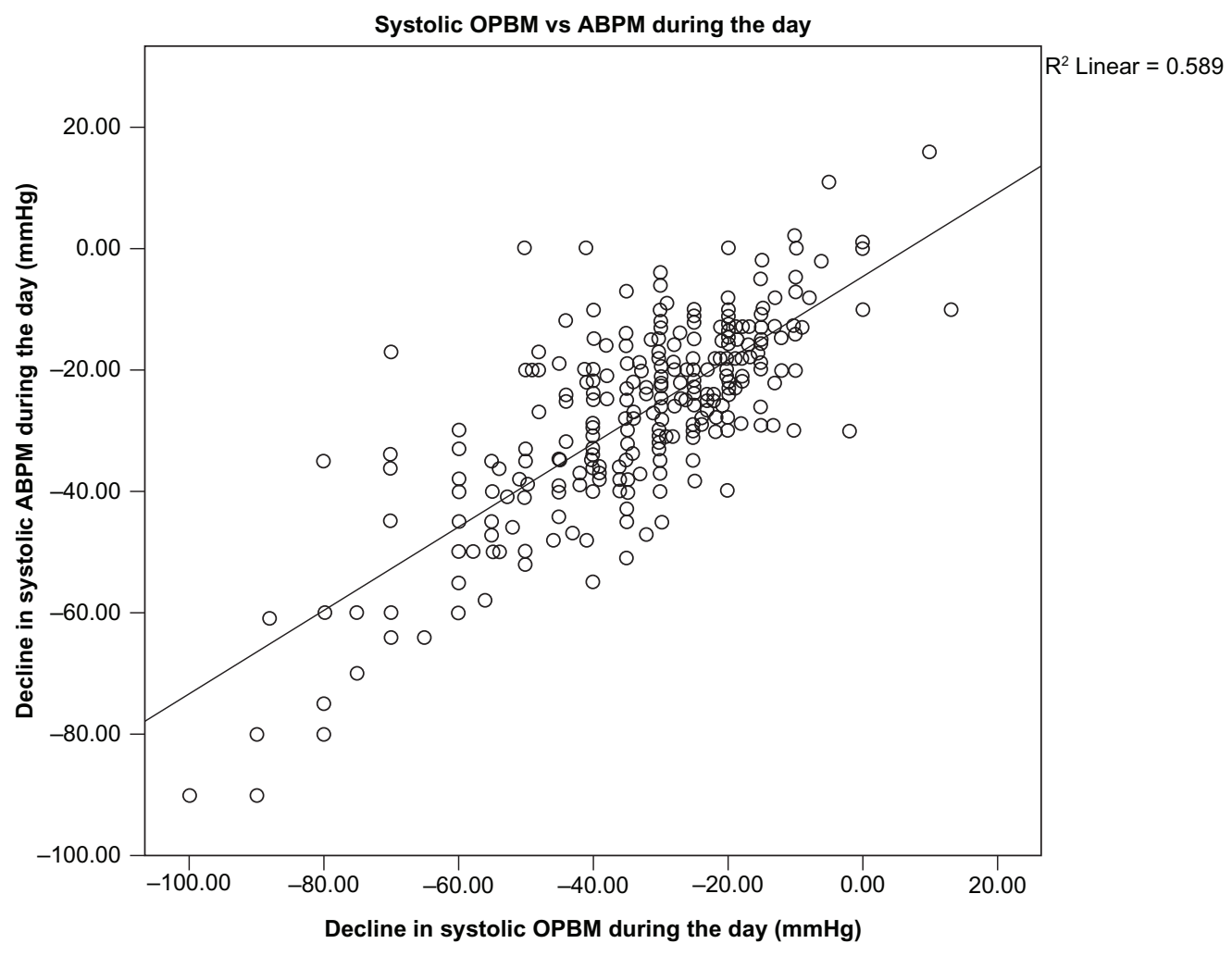

Figure I Systolic OPBM vs ABPM during the day.

Abbreviations: ABPM, ambulatory blood pressure measurement; OBPM, office blood pressure measurement. 


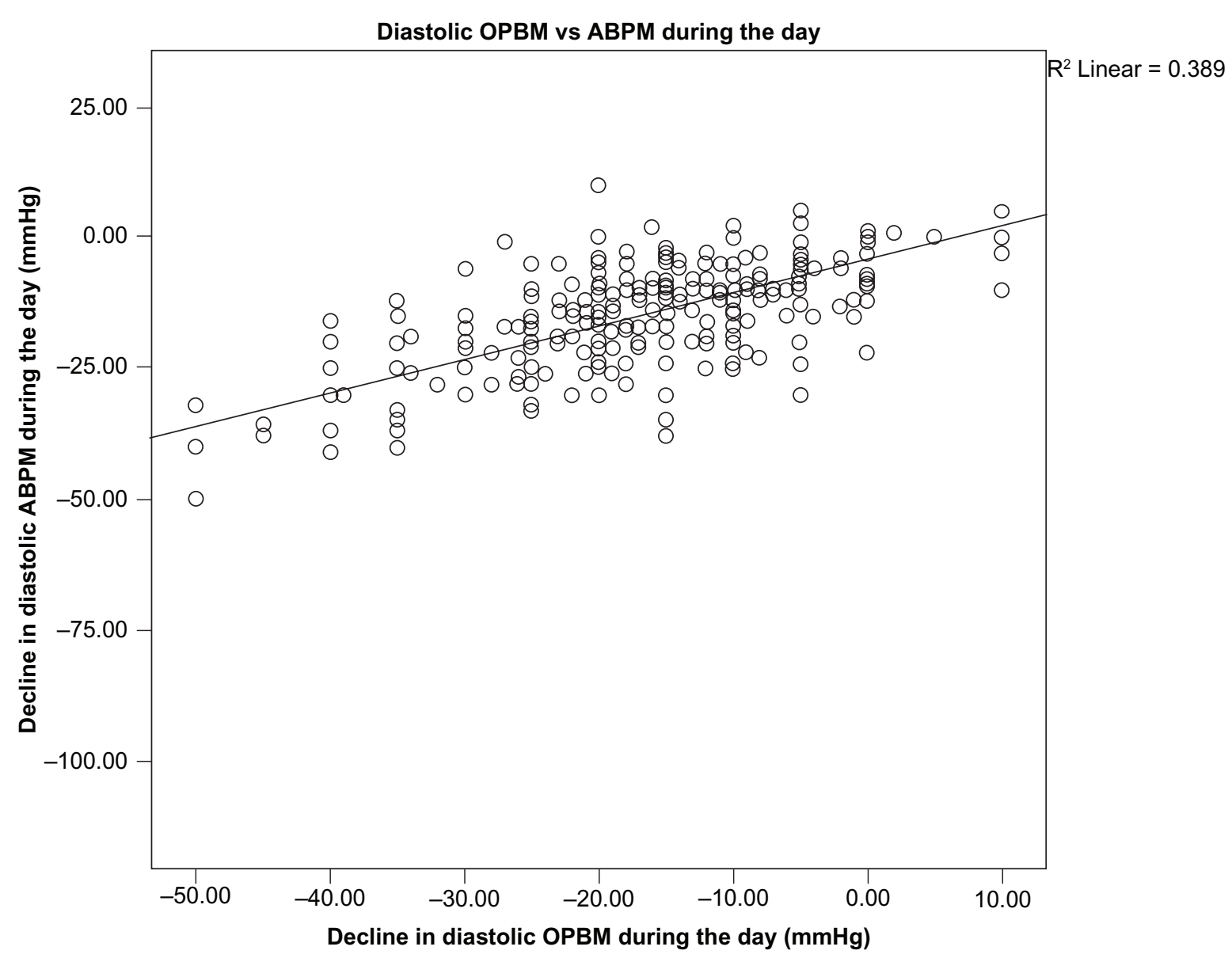

Figure 2 Diastolic OPBM vs ABPM during the day.

Abbreviations: ABPM, ambulatory blood pressure measurement; OBPM, office blood pressure measurement.

Table 5 Comparison of OBPM and ABPM blood pressure values

\begin{tabular}{|c|c|c|c|c|c|c|}
\hline & \multicolumn{6}{|c|}{ OBPM } \\
\hline & \multicolumn{2}{|c|}{$<140 / 90 \mathrm{mmHg}$} & \multicolumn{2}{|c|}{$\geq 140 \mathrm{mmHg}$ or $\geq 90 \mathrm{mmHg}$} & \multicolumn{2}{|c|}{ Total } \\
\hline & $\mathbf{n}$ & $\%$ & $\mathbf{n}$ & $\%$ & $\mathbf{n}$ & $\%$ \\
\hline \multicolumn{7}{|l|}{ ABPM day } \\
\hline Normal $(<135 / 85 \mathrm{mmHg})$ & 190 & 64.9 & 27 & 21.1 & 225 & 52.0 \\
\hline High ( $\geq 135$ or $\geq 85 \mathrm{mmHg}$ ) & 107 & 35.1 & 101 & 78.9 & 208 & 48.0 \\
\hline Total & 305 & 100.0 & 128 & 100.0 & 433 & 100.0 \\
\hline \multicolumn{7}{|l|}{ ABPM 24 hours } \\
\hline Normal $(<130 / 80 \mathrm{mmHg})$ & 79 & 26.7 & 9 & 7.1 & 88 & 20.8 \\
\hline High $(\geq 130 \mathrm{mmHg}$ or $\geq 80 \mathrm{mmHg}$ ) & 217 & 73.3 & 118 & 92.9 & 335 & 79.2 \\
\hline Total & 296 & 100.0 & 127 & 100.0 & 423 & 100.0 \\
\hline \multicolumn{7}{|l|}{ ABPM dipping } \\
\hline Normal dipper ${ }^{a}$ & 119 & 40.3 & 48 & 38.7 & 167 & 39.9 \\
\hline Nondipper ${ }^{b}$ & 147 & 49.8 & 64 & 51.6 & 211 & 50.4 \\
\hline Inverted dipperc & 10 & 3.4 & 7 & 5.7 & 17 & 4.1 \\
\hline Extreme dipper & 19 & 6.4 & 5 & 4.0 & 24 & 5.7 \\
\hline Total & 295 & 100.0 & 124 & 100.0 & 419 & 100.0 \\
\hline
\end{tabular}

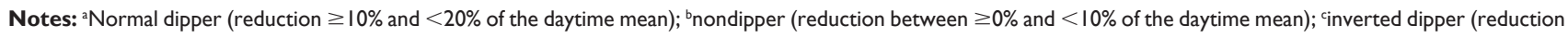

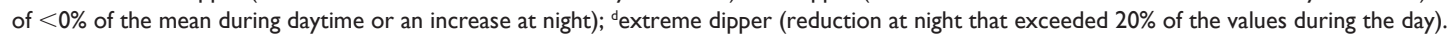

Abbreviations: ABPM, ambulatory blood pressure measurement; OBPM, office blood pressure measurement. 
Table 6 Number of patients with AEs or SAEs during survey and AEs coded by MedDRA ${ }^{\circledR}$ Version II.I (safety population, $\mathrm{n}=4|3|)$

\begin{tabular}{|c|c|c|}
\hline Type of adverse event & $\mathbf{n}$ & $\%$ \\
\hline No AE & 4082 & 98.81 \\
\hline Any $A E$ & 49 & 1.19 \\
\hline Serious $\mathrm{AE}$ & 7 & 0.17 \\
\hline Not serious & 42 & 1.02 \\
\hline \multicolumn{3}{|l|}{ MedDRA ${ }^{\circledR}$ Primary System Organ Class AEs } \\
\hline Nervous system disorders & 13 & 0.31 \\
\hline Cardiac disorders & 12 & 0.29 \\
\hline Investigations & 5 & 0.12 \\
\hline Skin and subcutaneous tissue disorders & 4 & 0.10 \\
\hline $\begin{array}{l}\text { General disorders and administration site } \\
\text { conditions }\end{array}$ & 3 & 0.07 \\
\hline Vascular disorders & 3 & 0.07 \\
\hline Musculoskeletal and connective tissue disorders & 3 & 0.07 \\
\hline Gastrointestinal disorders & 2 & 0.05 \\
\hline Renal and urinary disorders & 2 & 0.05 \\
\hline \multicolumn{3}{|l|}{ MedDRA ${ }^{\circledR}$ Primary System Organ Class SAEs } \\
\hline Nervous system disorders & 3 & 0.07 \\
\hline Vascular disorders & 1 & 0.02 \\
\hline Renal and urinary disorders & 1 & 0.02 \\
\hline Metabolism and nutrition disorders & 1 & 0.02 \\
\hline Cardiac disorders & 1 & 0.02 \\
\hline
\end{tabular}

Abbreviations: $A E$, adverse event; $S A E$, serious adverse event.

heart failure. After about 10 weeks of treatment, mean BP had lowered by $30.4 / 14.7 \mathrm{mmHg}$ from a baseline value of $162.1 \pm 14.8 / 94.7 \pm 9.2 \mathrm{mmHg}$. In a patient subgroup at risk, ABPM was performed and indicated that about $40 \%$ had a normal dipping pattern, whereas about $60 \%$ were nondippers or even inverted dippers.

\section{Effectiveness in clinical practice in the context of recent controlled trials}

The extent of BP reduction with candesartan/HCTZ depends on BP at baseline and the dose used. A variety of combinations with different doses of up to $32 \mathrm{mg}$ candesartan and up to $25 \mathrm{mg}$ HCTZ has been tested and found to be effective in clinical trials..$^{1,2,8,9}$ Uen et al, ${ }^{1}$ for example, demonstrated that replacing previously ineffective antihypertensive drugs with candesartan/HCTZ in patients with uncontrolled arterial hypertension significantly reduced BP and markers of ischemic stress such as ST-segment depression. In respect of the doses used in the present study, Edes ${ }^{2}$ observed mean reductions in SBP and DBP that were significantly greater with candesartan $32 \mathrm{mg} / \mathrm{HCTZ} 25 \mathrm{mg}(21 / 14 \mathrm{mmHg})$ than with candesartan $32 \mathrm{mg}(13 / 9 \mathrm{mmHg})$ or HCTZ $25 \mathrm{mg}$ alone $(12 / 8 \mathrm{mmHg})$ or placebo $(4 / 3 \mathrm{mmHg})(P<0.001$ for all comparisons $)$.
The proportion of patients with controlled BP (SBP < $140 \mathrm{mmHg}$ and DBP $<90 \mathrm{mmHg}$ ) at the end of this study was also significantly greater in the candesartan $32 \mathrm{mg} / \mathrm{HCTZ} 25 \mathrm{mg}$ group (63\%) than in the other treatment groups $(P<0.001$ for all comparisons $)$. Bönner ${ }^{3}$ investigated the efficacy of candesartan $32 \mathrm{mg}$ in combination with HCTZ $12.5 \mathrm{mg}$ or $25 \mathrm{mg}$ in patients who were not optimally controlled using candesartan monotherapy. Mean BP (153/97 mmHg at baseline) was further reduced by $13.0 / 8.8 \mathrm{mmHg}$ in the fixed combination with the HCTZ $12.5 \mathrm{mg}$ group and by $15.5 / 10.0 \mathrm{mmHg}$ in the fixed combination with HCTZ $25 \mathrm{mg}$ group $(P<0.01$ for all between-treatment comparisons). Against this background the results of the present noninterventional trial deserve to be noted, with a mean BP reduction of 30.4/14.7 $\mathrm{mmHg}$. BP reduction was consistent and similar across all subgroups of patients defined by prior but discontinued therapies, concomitant therapies, and cardiovascular risk at baseline.

\section{Comparison of OBPM and ABPM}

$\mathrm{BP}$ readings obtained by OBPM and $\mathrm{ABPM}$ were quite similar at baseline $(162.1 \pm 14.8 / 94.7 \pm 9.2 \mathrm{mmHg}$ vs $158.2 \pm 14.4 / 93.7 \pm 10.0 \mathrm{mmHg})$ and at follow-up (131.7 \pm $10.5 / 80.0 \pm 6.6 \mathrm{mmHg}$ vs $133.6 \pm 10.6 / 80.0 \pm 6.6 \mathrm{mmHg})$. There was also a high degree of correlation between OBPM and ABPM ( $r=0.589$ for SBP and $r=0.389$ for DBP) during the day in our study, which mirrors previous analyses that reported correlations coefficients of 0.41 for DBP (Mengden et al) ${ }^{10}$ and 0.73 for DBP and 0.64 for SBP (Head et al). ${ }^{11}$ Although the study by Mengden et $\mathrm{al}^{10}$ was a randomized controlled trial, the study by Head et $\mathrm{al}^{11}$ was a prospective cohort study that was biased toward those being referred for ambulatory assessment.

A high proportion of at-risk patients had normal BP readings during OBPM but a nondipping or even inverted dipping BP pattern at night. This may have been because of the noninterventional study type in which patients were scheduled only for ABPM when it was considered to be reasonable by the treating physician. In fact, about $60 \%$ of patients were documented to have either nondipping or inverted dipping of BP, suggesting that a tailored intervention (eg, bedtime medication) would be beneficial in those patients. On the other hand, the results clearly illustrate that achieving a normal BP during OBPM does not necessarily mean satisfactory BP control over 24 hours, reinforcing previous calls for a more comprehensive work-up of hypertensive patients, including ABPM. ${ }^{12}$ 


\section{Safety and tolerability}

Candesartan/HCTZ is generally well tolerated in patients with mild to moderate hypertension. Combined data from five randomized, double-blind, placebo-controlled clinical trials indicated that AEs during candesartan/HCTZ therapy are uncommon and that few were serious. ${ }^{13}$ The AE profile of candesartan $32 \mathrm{mg}$ in combination with $12.5 \mathrm{mg}$ or $25 \mathrm{mg}$ HCTZ, in particular, is likewise safe..$^{2,3}$ Bönner $^{3}$ reported about $1 \%$ serious AEs when candesartan combination therapy including HCTZ was considered. For metabolic parameters, a slight increase of serum ureate and serum creatinine was observed with the fixed combinations, whereas other parameters were essentially unchanged. Edes ${ }^{2}$ reported a rate of serious $\mathrm{AE}$ for the fixed-dose combination that was even lower compared with placebo $(0.2 \%$ vs $3.1 \%)$, with overall $\mathrm{AE}$ rate ranging between $23 \%$ and $25 \%$ for placebo, HCTZ, candesartan, and their combination. The present trial reassures that the high-dose fixed combination of candesartan and HCTZ is well tolerated, with $1.2 \%$ of patients having $\mathrm{AEs}$ and $0.2 \%$ having serious AEs, a proportion that is lower than the rates previously reported from randomized trials but about comparable with recent data from primary care. ${ }^{14}$ This is also consistent with findings that reported systematically lower AE rates in noninterventional studies than in randomized controlled trials, because of the lessened observation and reporting.

\section{Limitations}

Observational studies in primary care, including typical patient groups and reflecting current treatment approaches, are useful for complementing the findings of randomized controlled trials. ${ }^{4}$ The present results have to be considered against the background of potential limitations, however. First, the study was not controlled and therefore the role of a placebo effect or the withdrawal of antihypertensive agents is unknown. Second, in the absence of a randomization procedure, the influence of unknown biases, eg, through patient selection, cannot be ruled out. Third, because of the concurrent documentation of a $12.5 \mathrm{mg}$ and $25 \mathrm{mg} \mathrm{HCTZ}$ combination with $32 \mathrm{mg}$ candesartan and their addition to, or substitution for, other medications, bias cannot be ruled out. Fourth, because ABPM was not mandatory, the number of patients with both OBPM and ABPM is limited to about $25 \%$ of all patients. Because ABPM is usually performed in clinical practice in patients whose BP is difficult to control, ABPM may not be completely representative for the total OBPM population. ${ }^{12}$ This may explain the high proportion of nondipping patients.

\section{Conclusion}

Candesartan $32 \mathrm{mg}$ in a fixed-dose combination with either $12.5 \mathrm{mg}$ or $25 \mathrm{mg} \mathrm{HCTZ}$ is safe and effective for BP lowering in patients at high cardiovascular risk, irrespective of prior antihypertensive drug class not being able to control BP.

\section{Acknowledgments}

This noninterventional study was conducted by Takeda Pharma GmbH, Aachen, Germany. We would like to thank the participating physicians for their assistance and all patients observed during the study. Special gratitude goes to the clinical research organization Factum $\mathrm{GmbH}$ for data processing and conducting the statistical analyses. Takeda Pharma GmbH (Reinhold Hübner) designed the study. Thomas Mengden and Peter Bramlage explored the data and requested statistical analyses from the Factum $\mathrm{GmbH}$ (responsible statistician Dr Michael Vornkahl). Peter Bramlage wrote the first draft of the manuscript. Thomas Mengden and Reinhold Hübner revised the manuscript for important intellectual content. All authors reviewed and approved the final manuscript.

\section{Disclosure}

Thomas Mengden and Peter Bramlage have received research support and honoraria for medical consulting. Reinhold Hübner is an employee of the sponsor, Takeda Pharma GmbH.

\section{References}

1. Uen S, Un I, Fimmers R, Vetter H, Mengden T. Effect of candesartan cilexetil with hydrochlorothiazide on blood pressure and ST-segment depression in patients with arterial hypertension. Dtsch Med Wochenschr. 2007; 132(3):81-86.

2. Edes I. Combination therapy with candesartan cilexetil $32 \mathrm{mg}$ and hydrochlorothiazide $25 \mathrm{mg}$ provides the full additive antihypertensive effect of the components: a randomized, double-blind, parallel-group study in primary care. Clin Drug Investig. 2009;29(5):293-304.

3. Bönner G. Antihypertensive efficacy and tolerability of candesartanhydrochlorothiazide $32 / 12.5 \mathrm{mg}$ and $32 / 25 \mathrm{mg}$ in patients not optimally controlled with candesartan monotherapy. Blood Press. 2008; 17(Suppl 2):22-30.

4. Concato J, Shah N, Horwitz RI. Randomized, controlled trials, observational studies, and the hierarchy of research designs. $N$ Engl J Med. 2000;342(25):1887-1892.

5. Dolan E, Stanton A, Thijs L, et al. Superiority of ambulatory over clinic blood pressure measurement in predicting mortality: the Dublin outcome study. Hypertension. 2005;46(1):156-161.

6. Clement DL, De Buyzere ML, De Bacquer DA, et al. Prognostic value of ambulatory blood-pressure recordings in patients with treated hypertension. $N$ Engl J Med. 2003;348(24):2407-2415.

7. Salles GF, Cardoso CR, Muxfeldt ES. Prognostic influence of office and ambulatory blood pressures in resistant hypertension. Arch Intern Med. November 24, 2008;168(21):2340-2346.

8. Bramlage P, Schonrock E, Odoj P, Wolf WP, Funken C. Importance of a fixed combination of AT1-receptor blockade and hydrochlorothiazide for blood pressure lowering in cardiac risk patients. A postmarketing surveillance study with Candesartan/HCTZ. MMW Fortschr Med. 2008;149(Suppl 4):172-181. 
9. Azizi M, Nisse-Durgeat S, French Collaborative Group. Comparison of the antihypertensive effects of the candesartan $8 \mathrm{mg}$ hydrochlorothiazide $12.5 \mathrm{mg}$ combination vs the valsartan $80 \mathrm{mg}$ hydrochlorothiazide $12.5 \mathrm{mg}$ combination in patients with essential hypertension resistant to monotherapy [abstract no. P2.367]. J Hypertens. 2004;22(Suppl 2): S254-S255.

10. Mengden T, Binswanger B, Weisser B, Vetter W. An evaluation of selfmeasured blood pressure in a study with a calcium-channel antagonist versus a beta-blocker. Am J Hypertens. 1992;5(3):154-160.

11. Head GA, Mihailidou AS, Duggan KA, et al. Definition of ambulatory blood pressure targets for diagnosis and treatment of hypertension in relation to clinic blood pressure: prospective cohort study. BMJ. 2010;340:c1104
12. Luders S, Franz IW, Hilgers KF, et al. Twenty-four hour ambulatory blood pressure monitoring. Dtsch Med Wochenschr. 2005;130(46): 2664-2668.

13. Belcher G, Hubner R, George M, Elmfeldt D, Lunde H. Candesartan cilexetil: safety and tolerability in healthy volunteers and patients with hypertension. J Hum Hypertens. Sep 1997;11(Suppl 2):S85-S89.

14. Bönner G, Landers B, Bramlage P. Candesartan cilexitil/hydrochlorothiazide combination treatment versus high-dose candesartan cilexetil monotherapy in patients with mild to moderate cardiovascular risk (CHILI Triple T). Vasc Health Risk Manag. 2011;7:85-95.

\section{Publish your work in this journal}

Vascular Health and Risk Management is an international, peerreviewed journal of therapeutics and risk management, focusing on concise rapid reporting of clinical studies on the processes involved in the maintenance of vascular health; the monitoring, prevention and treatment of vascular disease and its sequelae; and the involvement of metabolic disorders, particularly diabetes. This journal is indexed on PubMed Central and MedLine. The manuscript management system is completely online and includes a very quick and fair peer-review system, which is all easy to use. Visit http://www.dovepress.com/ testimonials.php to read real quotes from published authors.

Submit your manuscript here: http://www.dovepress.com/vascular-health-and-risk-management-journal 